\title{
The Research on the Width of the Closed-Circuit Square-shaped Embroidery Element
}

\author{
Žaneta JUCHNEVIČIENE ${ }^{1}$, Milda JUCIENE ${ }^{1}$, Svetlana RADAVIČIENÉ ${ }^{2}$ \\ ${ }^{1}$ Institute of Architecture and Construction, Kaunas University of Technology, Tunelio St. 60, LT-44405, Kaunas, \\ Lithuania \\ 2 JSC “Tometa”, Draugystes Str. 19, LT-51230, Kaunas, Lithuania

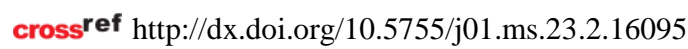

Received 20 August 2016; accepted 04 November 2016

\begin{abstract}
In modern manufacturing embroidered elements are used in such areas as implant production, rehabilitation (e.g., embroidered sensors), medical diagnostics, production of smart garments etc., where high accuracy is required to maintain the functionality of the product. Due to the influence of mechanical forces taking part in the embroidery process, the embroidery system is deformed, resulting in noncompliance of the embroidery element with the digitally designed one. Three fabrics have been selected as the objects of the research with the fiber composition of $65 \%$ polyester and $35 \%$ cotton, differing by weave and density. $60 \times 60 \mathrm{~mm}$ and $6 \mathrm{~mm}$ wide closed circuit square-shaped embroidery elements have been used for the research. According to the performed analysis of the results, the dimensions of the closed-circuit square-shaped embroidery element have changed in comparison to that of the digitally designed one. The width of the embroidery element, which was the most adequate to the digitally designed one, was achieved in the direction of warp. The obtained results have shown that in the corners the width of the embroidery element in the directions of warp and weft is bigger than the one in the centers of the segments.

Keywords: embroidered element, fabric, closed circuit.
\end{abstract}

\section{INTRODUCTION}

In the embroidery process, embroidery threads experience multiple tensile, they are affected by such factors as dynamic load, bending, friction, abrasion, etc. During embroidery the upper thread is most often thicker than the lower one, as the filling quality of the embroidered element is very important. When filling the embroidery area by various stitch directions and different stitch density, the lower thread loop shall be visible only from the back side, because the upper thread loop becomes bigger than the lower one in case of cross-over of threads. The upper embroidery thread occupies $2 / 3$, and the lower thread $-1 / 3$ of the embroidery area [1-2]. Due to influence of mechanical forces acting during the process, the embroidery systems are deformed and their physical properties are changed, the embroidered element does not match the actual size of the designed digital image. Therefore, it is important to define distinctions of deformation thereof [2-7].

The examination of the shapes of embroidered elements filled by mat type and their colour consistency has shown that the filling type and the stitch technology influence the element shape and colour uniformity [8]. The analysis of the influence made by the actual stitch density and direction of a round-shaped embroidered element on conformity of the shape to the designed digital image in some cases has demonstrated undesirable defects, such as outline irregularities of an embroidered element, puckering, and a hole inside the embroidered element [3]. The undesirable defects, shrinkage and puckering of the

\footnotetext{
* Corresponding author. Tel.: +370 37351627

E-mail address: zaneta.juchneviciene@ktu.edu (Ž. Juchnevičienė)
}

fabric are due to the relaxation processes observed in threads after the sewing process, which result in shrinkage of threads, reduced compaction between the fabric threads and puckering of the fabric $[1-2,9]$. Therefore, in order to prevent the defects, the physical and mechanical properties of fabrics and threads shall be determined.

Currently the electronic textiles and intelligent clothing is a rapidly growing sector all over the world, expanding use of embroidered intelligent conductive systems, where accuracy is a necessity. The researchers have determined that the use of different embroidery patterns and stitch density result in change of the electric field strength and textiles macro-fibres structure during the embroidery process. The results show that in case of an irregularly shaped embroidered element, variation of electrostatic force present in a square circuit increases the resonant amplitude, and the central wave frequency of $100 \mathrm{MHz}$ is reduced in the circuit [5]. In another study, researchers have integrated embroidered elements of different circuits with conductive multifilament piezoelectric yarn into a polyester glove with spandex, which have been used for monitoring the finger movements. During the analysis, after the rinse process of 15 minutes, the electrical resistance less than $500 \Omega /$ square has been established in the embroidered element. This has shown that during long-term use the embroidered electro-conductive system remains functional, and electrical resistance linearly increases with decreasing circuit of the embroidered area [10].

Thus it is crucial to ensure the compliance of an embroidered element with the designed shape.

A mathematical model composed on the basis of regression, which is used for analysis of the influence of 
Table 1. The characteristics of the fabrics

\begin{tabular}{|c|c|c|c|c|c|c|c|c|}
\hline \multirow{2}{*}{$\begin{array}{l}\text { Fabric } \\
\text { symbol }\end{array}$} & \multirow{2}{*}{ Composition } & \multirow{2}{*}{ Weave type } & \multicolumn{2}{|c|}{ Density, $\mathrm{cm}^{-1}$} & \multirow{2}{*}{$\begin{array}{c}\text { Surface } \\
\text { density, } \mathrm{g} / \mathrm{m}^{2}\end{array}$} & \multirow{2}{*}{$\begin{array}{c}\text { Thickness Ts (100), } \\
\text { mm with load }\end{array}$} & \multicolumn{2}{|c|}{ Linear density, tex } \\
\hline & & & $P_{\text {warp }}$ & $P_{\text {weft }}$ & & & $\mathrm{T}_{\text {warp }}$ & $\mathrm{T}_{\text {weft }}$ \\
\hline $\mathrm{A} 1$ & $\begin{array}{l}65 \% \text { PES, } \\
35 \% \text { cotton }\end{array}$ & Plain weave & 40 & 22 & 257 & 0.46 & 37 & 37 \\
\hline $\mathrm{A} 2$ & $\begin{array}{l}65 \% \text { PES, } \\
35 \% \text { cotton }\end{array}$ & Twill 4/1 & 45 & 29 & 287 & 0.56 & 37 & 40 \\
\hline A3 & $\begin{array}{l}65 \% \text { PES, } \\
35 \% \text { cotton }\end{array}$ & Twill 3/1 & 39 & 19 & 251 & 0.65 & 30 & 50 \\
\hline
\end{tabular}

embroidery process technological factors to the embroidery process malfunctions, has shown that the malfunctions are most affected by selection of fabrics with incorrect mechanical properties, incorrect needle size and inappropriate selection of embroidery threads [11]. But a closer analysis of the embroidered element quality or geometric parameters has not been performed.

After the research [12] Chinese scientists have divided embroidered elements into four groups that are identified in an automated way. The identification method of the embroidered elements defects enables automated inspection procedures in the embroidery textile industry. In the investigated case, while developing the classification of embroidered elements defects and carrying out a visual assessment thereof, the geometric parameters of the embroidered elements shape are not analysed.

During the development of the state-of-the-art technologies that allow to integrate embroidered systems in line with the traditional textile fibres, as well as the electroconductive embroidered systems into fully completed textile structures, the requirements of the automated embroidery process quality are inevitably increasing. For application of diversity of the embroidered elements and improvement of quality, embroidery technical installations are developed and improved, as well as digital software shaping packages, etc. Therefore, the embroidered elements quality is widely investigated by researchers of various countries. However, subjects analysing the determinants affecting accuracy of embroidered elements shape are not widely researched.

The scientific researches show that the physical properties of the fabric structure and the differences in stitch formation influence the quality of embroidered systems. During shaping of stitches in the embroidery process the fabric is retracted in the embroidery direction, thus at a larger number of stitch threads fabric threads are less in contact perpendicular to the embroidery direction, and as such their threads are expanding. Usually, seam slippage is observed in twill weave fabrics, sateen, plain weave fabrics, etc. These defects are defined by offset caused by force acting perpendicular to the seam [2-3].

The objective of the work is to research the compliance of the width of the closed circuit squareshaped embroidery element with the width of the digitally designed one.

\section{EXPERIMENTAL DETAILS}

Fabrics selected as objects of research are of the same composition, similar in surface density and density (Table 1). Polyester embroidery threads have been used for the research: the upper thread-of 2-ply spun yarn, twist direction $\mathrm{Z}$ (multifilament), the linear density of the thread-30,2 tex; and the lower thread-of 2-ply-spun yarn branches, twist direction $\mathrm{Z}$ (yarn), the linear density of the thread $-24,7$ tex.

Embroidery process has been performed using embroidery machine BEXT-S901CAII with one head, at the embroidery speed $\mathrm{V}=800 \mathrm{~min}^{-1}, 60 \times 60 \mathrm{~mm}$ and $6 \mathrm{~mm}$ wide closed-circuit square elements have been embroidered for the research. The digital close-circuit square images have been designed using software package Wilcom Embroidery Studio E2. The embroidered area is filled using embroidery type T (Fig. 1).

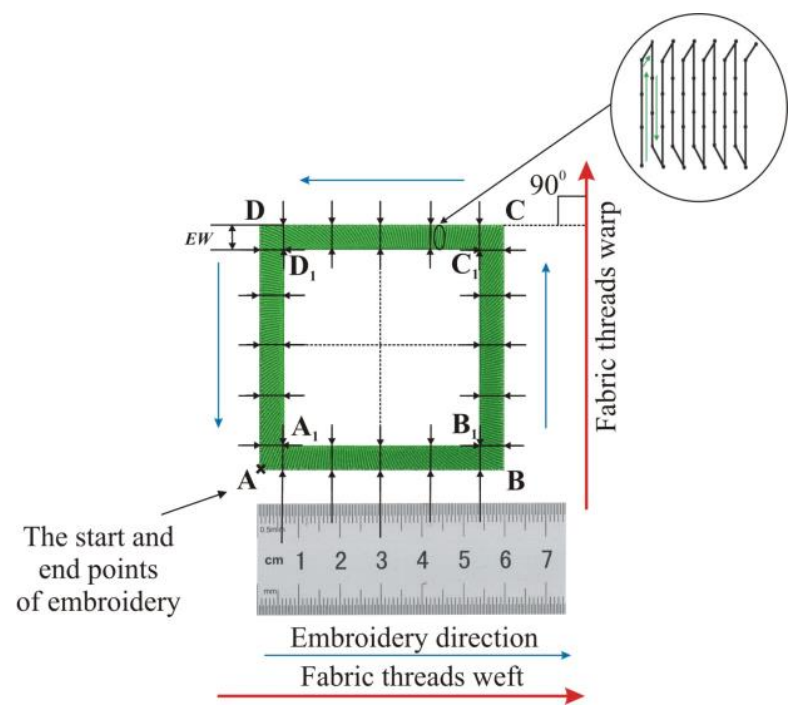

Fig. 1. The width measurement diagram of the embroidered closed-circuit square element, where $E W$-the circuit width of the embroidered element

Using filling type $T$, the stitch length is fixed by the needle piercings from one edge of the embroidered element to the other, by making the sequence of stitches and needle piercings. The sides of the closed-circuit square embroidered elements are parallel to the fabric threads systems, therefore it is possible to assess the influence of the textile fabric properties and the embroidery direction on the shape stability. 6 samples of each fabric under investigation have been embroidered during the research. The width measurement diagram of the embroidered element circuit is provided in Fig. 1.

Width measurements are carried out in all square sides within the length and height of the element: at corners - at the intersection points of the inside circuits, and every $12 \mathrm{~mm}$, where the central point is in accordance with the side centre. 
The embroidery process of the closed-circuit square shape begins with point $A$, moves counterclockwise toward points $\mathrm{B}, \mathrm{C}, \mathrm{D}$ and ends at the initial point $\mathrm{A}$. In one case the embroidery direction is in the weft thread direction (sides $\mathrm{AB}, \mathrm{CD}$ ), and in another case it is parallel in the warp thread direction (sides BC, DA) (Fig. 1). The circuit width $E W$ of the embroidered square samples is measured using software package COREL DRAW 12.

The research analyses the estimated average width of the embroidered element. The overall relative incorrectness of the results of measurements was ranging from $1 \%$ to $5 \%$. The coefficient of variation has not exceeded $5 \%$.

\section{RESULTS AND DISCUSSION}

The analysis of the circuit width $E W$ of the closedcircuit square embroidered element and comparison thereof with the width of the designed element have shown that the width $E W$ of fabrics of different weave differs in the warp and weft directions and in most of the cases does not comply with the designed one. The analysis and comparison of the square circuit width $E W$ of the embroidered element have shown that the circuit width of segments BC and DA in the warp direction is not the same. The average circuit width $E W$ of the plain weave fabric A1 estimated in the segment BC of the warp direction is $\sim 1,7 \%$ lower than the designed width; while the circuit width $E W$ in another segment DA of the warp direction complies with the designed width. The circuit width $E W$ of the twill weave fabric A2 in the segment BC of the warp direction is unequal: at one corner the estimated value is $\sim 1,7 \%$ higher than the designed one, while at another corner it complies with the designed value; and at other segment points the estimated value is $\sim 1,7 \%$ lower than the designed circuit width $E W$. In most cases the estimated circuit width $E W$ of fabric A2 in segment DA is $~ 3.3 \%$ higher than the designed circuit width. The estimated circuit width $E W$ of fabric A3 in the warp direction in segment $\mathrm{BC}$ is $\sim 3.3 \%$ lower than the designed circuit width, while in another segment DA the estimated circuit width is mostly $\sim 1.7 \%$ lower than the designed circuit width. A peer comparison of all circuit width values of the embroidered elements segments of all the analysed fabrics in the warp direction has shown that the width of fabric A2 is the closest to the designed value $E W$ in segment $\mathrm{BC}$, and the width of fabric A1 - in segment DA.

The analysis has shown that the circuit width $E W$ at the corners (Fig. 2) in most cases is wider than at the segment centres of the embroidered element. Such a behaviour of different weave fabrics can be explained by the structural distinctions of the fabric. On the front side of the twill weave fabric A2 and A3 there are more warp floats (Table 1) that rise from left to right. Due to differences in thread number of the weave floats and other distinctions the thread floats contact fields have free fields which give rise to the possibility for compaction of two threads of the same system and liquidate gap between them.

During the embroidery process, when a needle pierces the fabric structure at high speed, in the contact textile fabric and thread surface systems there occurs resistance force due to the existence of thermal shock, and thus the fibres are compressed within the fabric structure, and the threads change their position.

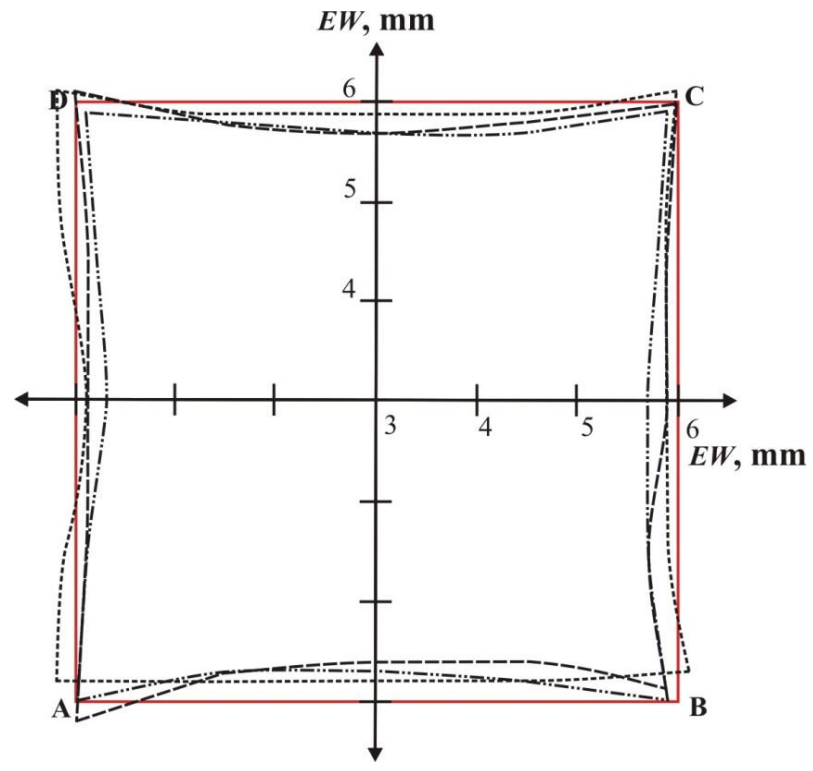

Fig. 2. The actual width $E W$ of the closed-circuit square embroidered element, where - - the width of the designed element, --- - the embroidered element accomplished on fabric A1, -..--..--the embroidered element accomplished on fabric A2, $\cdot-\cdots$ - the embroidered element accomplished on fabric A3.

The research has shown that the samples embroidered on plain-weave fabric A1 in the warp direction are most distinct from the designed circuit width $E W$, where the average value of the circuit width $E W$ is $\sim 1,7 \%$ lower than the designed one. The most precise circuit width $E W$, which complies with the designed circuit width (the average value of the circuit width $E W$ is $6 \mathrm{~mm}$ ), has been obtained in embroidering the samples on the twill weave fabric A2 in the warp direction (Fig. 3). The deformation behaviour is highly affected by fabric structure, direction and mechanical properties. The homogeneous floats of plain-woven fabrics are in contact at all corners, and the thread contact fields do not have free fields. In such weaving types the opposite warp and weft floats compose coherent connection fields, where the corrective effective force resists the thread compaction [13-15]. The previous researches have shown that in twill weave fabric structure thread float connection fields are weakened due to formation of free fields, and the compaction is increasing depending on physical properties [1-4, 13-15]. Because of mechanical influence the fabric is compressed and buckled inside the embroidered element $[3,16,17]$. As a consequence, floats of the twill weave fabric are in contact, the contacting diagonal homogeneous thread corners of the fabric structure are distorted, and the weaving threads irreversibly change their position while offsetting. Hence, in this case the embroidered element of the twill weave fabric A2 with the surface density of $\mathrm{g} / \mathrm{m}^{2} \sim 12,5 \%$ higher than the one of other analysed fabrics is close to the designed circuit width $E W$.

The analysis of the results has shown that the circuit width $E W$ of different weave fabrics in the warp direction in most cases had been higher than the one obtained in the weft direction (Fig. 3). The scientists have determined that 
penetration of the needle deform the fabric structure more in the warp direction than in the weft one. It has been determined that in fabrics with density in the weft direction of $26 \mathrm{~cm}^{-1}$ the penetration force had changed from $75 \mathrm{cN}$ to $138 \mathrm{cN}$, while in other samples, where the density in the weft direction is higher $-32 \mathrm{~cm}^{-1}$, the penetration force had also been higher and had changed from $218 \mathrm{cN}$ to $370 \mathrm{cN}$ [18]. The thread density of the analysed fabrics in the weft direction is $\sim 35 \%$ to $\sim 51 \%$ lower than the one in the warp direction; therefore, during relaxation processes in the weft direction threads are more compacted and closer in contact with one another than it is the case in the warp direction. It should be noted that the filling type and direction also affects the difference of the circuit width $E W$ of an embroided element in fabric directions. Closedcircuit square elements have been embroided from the external circuit in stitch rows to the inner circuit edge of the element, and the corners are formed from the greater number of stitches than in case of the side oblique stitch rows. The estimated width differences can be explained by a large concentration of stitches at the corners of the closed-circuit square embroidered element, when fabric threads move due to power perpendicular to the embroidery direction [19].

It has been determined that the internal circuit width of $5.8 \mathrm{~mm}$ of the embroidered fabric A3 is the same in both the warp and weft directions and to the utmost noncomplying with the designed circuit width; the final embroidered element is $\sim 1,7 \%$ smaller than the designed width (Fig. 3). The fabric between embroidery stitches is compressed due to the relaxation processes occurring in threads and due to anisotropy of the fabric, thereby decreasing dimensions of embroidered element and causing other defects $[2,3,16,17]$.

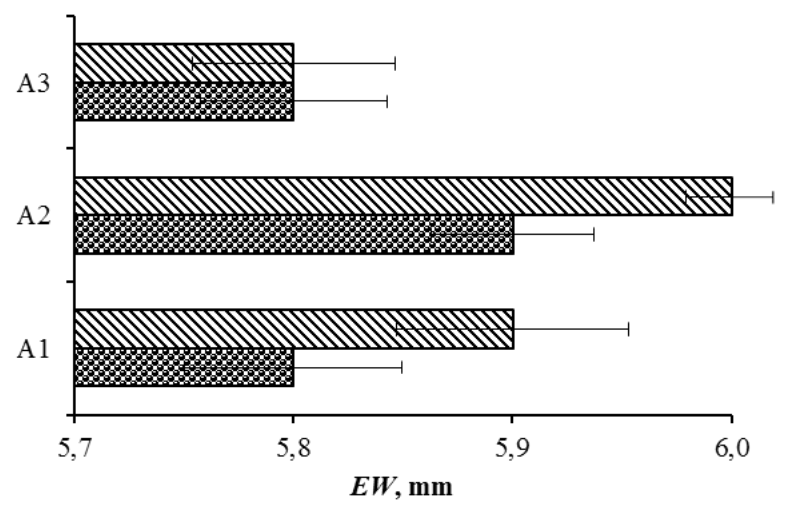

Fig. 3. The average actual width $E W$ of the embroidered closedcircuit square element, where $\mathbb{\mathbb { N }}$ - the circuit width of the embroided element in the warp direction, 洫 - the circuit width of the embroided element in the weft direction

During the analysis, it has been noted that in many cases the circuit width of the embroidered element $E W$ in the warp and weft directions is greater at corners than in the section centres. It has been determined that the circuit width $E W$ of the embroidered element at the corners of fabric A2 in the warp direction has been the largest and $\sim 1,7 \%$ to $\sim 3,3 \%$ wider than the circuit centre and the designed one. The estimated circuit width $E W$ of the embroidered element in the weft direction at the corners has been lower than the one in the warp direction. In this case the circuit width has not been always estimated as higher than the designed one, however it has been higher than the one at the circuit centre (Fig. 2). During the analysis of the circuit width at the corners, it has been noted that the widest circuit has been obtained at the end of the embroidery cycle, i.e., on side DA, while forming the last stitch rows at the point A. At the end of the embroidery cycle the needle becomes hot due to thermal effect, and new connections are formed between contacting systems at the piercing spots. The performed analysis shows that the force of the needle piercing affects these connections and depends on the fabric weave, density, linear density, etc. $[9,13,18]$. It is likely that the results obtained are affected by filling type $\mathrm{T}$ of the closed-square. The width of the embroidered element of filling type $\mathrm{T}$ consists of a row of embroidery stitches. The needle penetrates the fabric in one segment $\sim 490$ times, and four times more in the whole closed-square. In this case, in order to obtain a closed shape, longer stitch rows of oblique direction are formed at the square corners and the number of stitches in a row increases at the corners. In this way the corner outlines are filled and shaped. Due to multiple needle piercing and number of insertions of embroidery threads into the embroidered element, the structure floats of the elements embroidered by filling type $\mathrm{T}$ are being developed and cannot get in contact alongside each other, therefore a greater width of the embroidered elements is in most cases obtained precisely at the corners, as compared to other places of an embroidered element.

During the embroidery process, when the element is embroided from the external circuit in stitch rows to the inner circuit of the element, relaxation processes are taking place in the embroidery systems. In the course of relaxation, upon start of the initial pretension, fibre systems react very soon, and subsequently, the said response rate is slowing down until the so-called "balance" is settled. When the external force does not affect fibres, such relaxing systems return to its initial position balance at the gradually decreasing speed [1, 9, 13, 17].

The analysis has shown that the research allows to identify and evaluate the non-conformity of the closedcircuit square embroidered element to the designed value by analysing the embroidery process in both fabric thread directions. It has also been determined that the filling type and the stitch direction influence the width $E W$ of the closed-circuit square embroidered element, depending on the characteristics of the fabric.

\section{CONCLUSIONS}

The analysis of the results of the performed research has shown that the width of the closed- circuit squareshaped contour in comparison to the width of the digitally designed element in most cases does not match. In all researched cases it has been determined that the width of the side of the square shaped embroidery element completed in the direction of warp is received more adequate to the digitally designed one than in the direction of weft. Therefore, in order to get the embroidery element of more accurate dimensions, it is necessary to evaluate the properties of the materials in different directions. 
It has been determined that in most cases the width of the embroidered element in the corners of the square is bigger than in the centers of the segments. In this case, the stitches go in different angles in relation to the thread system of the fabric and the fabric is penetrated more times in one segment. Thus, not only the width of the element differs in the corners but also the shape of the element is distorted in some cases.

The carried out researches showed that the squareshaped embroidery element allows to evaluate the quality of the embroidery element in all directions of the fabric and it can be valuable while assessing the reasons of different defects and also while forming new modules of embroidery products and standards.

\section{REFERENCES}

1. Radavičienè, S., Jucienė, M. Influence of Embroidery Threads on the Accuracy of Embroidery Pattern Dimensions Fibres \& Textiles in Eastern Europe 20 (3) 2012: pp. 92-97.

2. Chernenko, D.A. Systematization of Design Parameters for Automated Embroidery and Modelling of Deformation System of "Fabric-Embroidery“" Ph. D. Thesis Orel, Russia 2006: 132 p.

3. Radavičienè, S., Jucienè, M., Juchnevičienė, Ž., Čepukonè, L., Vilumsone A., Briedis, U., Baltina, I. Analysis of Shape Nonconformity between Embroidered Element and Its Digital Image Materials Science (Medžiagotyra) 20 (1) 2014: pp. 84-89.

4. Shafi, A., Yosouf, K., Schacher, L., Adolphe, D.-C. Effect of Stitch Density on Shear Properties of Embroidered Metallic Circuit and Impact of Pressure on Sensor During Movement Book of the Proceeding of the 6th International Textile Clothing \& Design Conference-Magic World of Textiles 2012: pp. 424-429.

5. Tsolis, A, Whittow, W.G., Alexandridis, A.A., Vardaxoglou, J.C. Embroidery and Related Manufacturing Techniques for Wearable Antennas: Challenges and Opportunities Electronics 3 2014: pp. 314-338.

6. Maleszka, T., Kabacik, P. Bandwidth Properties of Embroidered Loop Antenna for Wearable Applications Book of the Proceeding of the 3rd European Wireless Technology Conference 2010: pp. 89-92.

7. El-Gholmy, S, Bondok, N, El-Geiheini, A. Optimization of embroidery design on denim fabrics Book of the Proceeding of the 5th International Textile, Clothing \& Design Conference 2010: pp. 821-826.

8. Shih, C.Y., Kuo, C.F.J., Cheng, J.H. A Study of Automated Color, Chape and Texture Analysis of Tatami Embroidery Fabrics Textile Research Journal 86 (17) 2016: pp. $1791-1802$.

9. Radavičienè, S., Jucienė, M. Investigation of Mechanical Properties of Embroidery Threads Book of the Proceeding of the 5th International Textile, Clothing \& Design Conference 2010: pp. 494-499.

10. Akerfeldt, M., Lund, A., Walkenström, P. Textile Sensing Glove with Piezoelectric PVDF Fibers and Printed Electrodes of PEDOT: PSS Textile Research Journal 85 (17) 2015: pp. 1789- 1799. https://doi.org/10.1177/0040517515578333

11. El-Kateb, S.N. An investigation of Factors affect Endsdown Rate in Embroidery Machine Journal of American Science 11 (6) 2015: pp. 39-42.

12. Kuo, C.F.J., Juang, Y. A study on the Recognition and Classification of Embroidered Textile Defects in Manufacturing Textile Research Journal 86 (4) 2016: pp. 393-408.

13. Pocienė, R., Vitkauskas, A. Inverse Stress Relaxation in Textile Yarns After the Blockage of Viscoelastic Recovery Materials Science (Medžiagotyra) 13 (3) 2007: pp. $240-244$.

14. Pavlinič, D.Z., Geršak, J. Investigations of the Relation Between Fabric Mechanical Properties and Behaviour International Journal of Clothing Science and Technology 15 (3/4) 2003: pp. $231-240$.

15. Hosseinali, F. Investigation on the Tensile Properties of Individual Cotton (Gossypium hirsutum L.) Fibers Texas Tech University, Farzad Hosseinali 2012: pp. 1-76.

16. Rudolf, A., Geršak, J., Ujhelyiova, A., Smole, M.S. Study of PES Sewing Thread Properties Fibers and Polymers 8 (2) 2007: pp. $212-217$. https://doi.org/10.1007/BF02875794

17. Rudolf, A., Geršak, J. Influence of Sewing Speed on the Changes of Mechanical Properties of Differently Twisted and Lubricated Threads during The Process of Sewing Tekstil 56 (5) 2007: pp. 271-277.

18. Gurarda, A., Meric, B. The Effects of Elastane Yarn Type and Fabric Density on Sewing Needle Penetration Forces and Seam Damage of PET/Elastane Woven Fabrics Fibres \& Textiles in Eastern Europe 15 (4) 2007: pp. 73-76.

19. Bačkauskaitė, D., Daukantienė, V. Investigation of Wear Behaviour of Sewn Assemblies of Viscose Linings with Different Treatment Materials Science (Medžiagotyra) 17 (2) 2011: pp 155-159.

20. Shan, H., Yong, C. An Algorithm of Finding Path of Embroider Suture Needle Chine Journal of Computers 26 (9) 2003: pp. $1211-1216$.

21. Bekampienè, $\mathbf{P}$., Domskienè, J. Influence of Stitching Pattern on Deformation Behaviour of Woven Fabric during Forming Materials Science (Medžiagotyra) 6(3) 2010: pp. 226-230.

22. Dobilaitė, V., Jucienė, M. The Influence of Mechanical properties of Sewing Threads on Seam Pucker International Journal of Clothing Science and Technology 18 (5) 2006. pp. $335-345$.

23. Dobilaitė, V., Petrauskas, A. The Method of Seam Pucker Evaluation Material Science (Medžiagotyra) 9 (1) 2002: pp. 209-212. 